\title{
Implications of Monomer Deformation for Tetrel and Pnicogen Bonds
}

\author{
Wiktor Zierkiewicz, ${ }^{* 1}$ Mariusz Michalczyk ${ }^{1}$ and Steve Scheiner*2 \\ ${ }^{1}$ Faculty of Chemistry, Wrocław University of Science and Technology, Wybrzeże Wyspiańskiego 27, \\ 50-370 Wrocław, Poland \\ 2 Department of Chemistry and Biochemistry, Utah State University, Logan, \\ Utah 84322-0300, United States
}

\begin{abstract}
A series of $\mathrm{TF}_{4}$ and $\mathrm{ZF}_{5}$ molecules $(\mathrm{T}=\mathrm{Si}, \mathrm{Ge}, \mathrm{Sn}$ and $\mathrm{Z}=\mathrm{P}, \mathrm{As}, \mathrm{Sb})$ were allowed to engage in tetrel and pnicogen bonds, respectively, with $\mathrm{NH}_{3}$, pyrazine, and $\mathrm{HCN}$. The interaction energies are quite large, approaching $50 \mathrm{kcal} / \mathrm{mol}$ in some cases. The formation of each complex is accompanied by substantial geometrical deformation of the Lewis acid to accommodate the approaching base. The energy associated with this monomer rearrangement is largest for the smaller central atoms Si and P, where it exceeds $20 \mathrm{kcal} / \mathrm{mol}$. The total reaction energy of binding, which takes this distortion energy into account, is thus significantly lower than the interaction energy, although remaining quite high, particularly for the larger $\mathrm{Sn}$ and $\mathrm{Sb}$ central atoms. The tetrel and pnicogen bonds can still form even if the Lewis acid is not permitted to adjust its internal geometry, but they are drastically weakened, dropping by as much as 95\%. The monomer rearrangement also aids in the binding by intensifying its $\sigma$-hole by a factor of 1.5-2.9.
\end{abstract}

Keywords: $\sigma$-hole; molecular electrostatic potential, energy decomposition

*Correspondence to: wiktor.zierkiewicz@pwr.edu.pl, steve.scheiner@usu.edu 


\section{Introduction}

Although numerous noncovalent interactions play a vital role in a widespread range of chemical and biological processes, it was the hydrogen bond $(\mathrm{HB})$ that captured the lion's share of attention over the years. ${ }^{1-3}$ The introduction ${ }^{4}$ and further expansion of the application of interactions parallel to the HB triggered increased interest in the scientific community. ${ }^{5-11}$ In particular, these new types of bonds replaced the bridging proton by halogen, ${ }^{12-15}$ chalcogen, ${ }^{16-19}$ pnicogen ${ }^{20-23}$ and tetrel ${ }^{24-27}$ atoms and these bonds were named accordingly. Despite the electronegativity of these atoms, they were able to avoid electrostatic repulsion with an approaching nucleophile due to the anisotropy ${ }^{9}$ of the molecular electrostatic potential (MEP) surrounding the atom of interest. A positive area, commonly referred to as a $\sigma$-hole, is located directly opposite the R-X bond and is able to attract the negative potential of the approaching base. ${ }^{411}$ This Coulombic component of the attraction is supplemented by ample contributions from polarization and dispersion effects ${ }^{28-30}$. Its generality extends even to the aerogen group ${ }^{31-33}$ despite the very low reactivity of these inert atoms.

In the specific case of the pnicogen bond ${ }^{4,34}$, the majority of computational study has focused on interactions of substituted phosphines $\left(\mathrm{PH}_{2} \mathrm{X}\right)$ with a variety of electron donors. ${ }^{37-41} \mathrm{In}$ most cases this bond energy is less than about $15 \mathrm{kcal} / \mathrm{mol}$, with the exception of very strong anionic nucleophiles such as $\mathrm{F}^{-} \cdot{ }^{42} \mathrm{The}$ strength of this bond can be adjusted by substitution of electron-withdrawing or donating groups on either the Lewis base or acid, or by varying the identity of the pnicogen atom itself: ${ }^{43-45}$ Larger pnicogen atoms are associated with stronger bonds. The properties of these intermolecular interactions can also be regulated by cooperative effects involving additional molecules beyond the simple dimer. ${ }^{46-48}$ Very similar statements can be made about tetrel bonds. ${ }^{49-55}$ In principle, the lesser electronegativity of the tetrel vs the pnicogen atom lends them a more intense $\sigma$-hole which would tend ${ }^{53}$ toward a stronger bond. On the other hand, the tetrahedral arrangement of four substituents around the central tetrel atom is subject to issues of steric crowding when a nucleophile attempts to fit its way in.

Due to the usefulness of both pnicogen and tetrel bonds in the fields of molecular recognition, supramolecular chemistry, and organic synthesis, ${ }^{56-62}$ it is important to have a full understanding of their fundamental nature and properties. While information is rapidly accumulating, there are several important aspects which bear more active scrutiny. For example, recent calculations ${ }^{63,64}$ observed that a series of pentavalent $\mathrm{ZX}_{5}(\mathrm{Z}=\mathrm{P}, \mathrm{As}, \mathrm{Sb}$ and $\mathrm{X}=\mathrm{F}, \mathrm{Cl}, \mathrm{Br})$ molecules undergo very substantial rearrangement upon formation of a pnicogen bond with a N-base. This finding dovetails with the distortions arising in $\mathrm{TR}_{4}$ molecules $(\mathrm{T}=$ tetrel) due to their crowded nature. So the issue of steric crowding as it relates to monomer deformation upon formation of both pnicogen and tetrel bonds comes immediately to the fore.

How does the crowding affect the buildup of positive charge in the development of $\sigma$-holes; can such holes even occur at all, given the close proximity of the various substituents around the central atom? As the 
nucleophile approaches, the Lewis acid undergoes very substantial geometric rearrangement. Do these changes occur smoothly or precipitously at a particular intermolecular distance? What are the effects of these changes in nuclear position upon the location and intensity of each $\sigma$-hole, and how do these changes affect the electrostatic attractive force between the two molecules? Since it is not only the electrostatic term which is involved in these bonds, it is important to address the effects of geometrical distortion upon the other components such as polarization and dispersion. How large an energetic consequence attends the internal rearrangement arising from the interaction, and how might this affect the overall binding energy? If the monomers are unable to distort sufficiently, as might occur in a restricted macromolecular environment, what will be the implications for the intermolecular bonding?

This work considers these questions in the context of eighteen different model systems, comprising both tetrel and pnicogen bonds, incorporating atoms from three different rows of the periodic table, and using a series of bases, both large and small, and covering a range of electron-donating ability. The calculations follow the formation of each bond in stages as the two molecules approach one another, monitoring the degree of geometric distortion along the way. The intensity of the $\sigma$-holes on the Lewis acid, as well as their positions within the molecule, are carefully monitored as well. Decomposition of the interaction energy enables analysis of the manner in which the deformations affect each component of the total during the bond formation process. The data provide insights into the interplay between geometric distortion and attractive forces, and what one might expect if such deformations were restricted by macromolecular constraints.

\section{Systems and Methods}

Due to the strong electron-withdrawing capacity of F, perfluorinated molecules have been observed to engage in some of the strongest complexes of this type. ${ }^{63}$ So the perfluorinated $\mathrm{TF}_{4}$ molecules were taken as the tetrel-bonding Lewis acids. In order to elucidate the variations that occur depending upon the particular tetrel atom, Si, Ge, and $\mathrm{Sn}$ were taken in turn as the central $\mathrm{T}$ atom. With regard to the pnicogen atom $\mathrm{Z}$, studies of the trivalent $\mathrm{ZF}_{3}$ bonding state ${ }^{20,65-76}$ have shown only small indications of steric crowding inducing monomer deformation. Pentavalent $\mathrm{ZR}_{5}$, on the other hand, can be expected to be subject to more stringent steric repulsions in order to accommodate a sixth ligand. Moreover, $\mathrm{ZF}_{5}$ has not been the subject of extensive prior work so much of its ability to engage in a pnicogen bond remains to be elucidated. Nor is this an uncommon bonding situation for pnicogen atoms so its examination will be of some real relevance. ${ }^{77-93} \mathrm{ZF}_{5}$, was thus taken as pnicogen-bonding molecule, with $\mathrm{Z}=\mathrm{P}, \mathrm{As}$, and $\mathrm{Sb}$, to again determine dependence upon size of pnicogen atoms. Three different bases were considered so as to cover a range of electron-donating power. $\mathrm{NH}_{3}$ is a small base as is $\mathrm{NCH}$, but with differing hybridization and basicity of the $\mathrm{N}$ atom. Pyrazine is a larger molecule that might incur more severe steric issues as it engages in dimerization with each of the Lewis acids. 
All calculations were performed at the MP2 level in conjunction with the cc-pVTZ basis set. ${ }^{94,95}$ For the Sb and Sn atoms, the cc-pVTZ-PP basis set which includes relativistic effects was applied. ${ }^{96,97}$ In all cases of optimized structures, vibrational frequencies were calculated in order to confirm that the structures correspond to true minima. The binding energy of each complex was calculated as the energy difference between the complex and the sum of the individually optimized monomers. The interaction energy takes as its reference the energies of the monomers measured in the geometries assumed within the complex. These two quantities thus differ by the sum of the deformation energies of the monomers, defined as the energy required to distort each monomer from its optimized geometry to that within the dimer. The interaction and binding energies of the complexes were corrected for basis set superposition error (BSSE) by the standard counterpoise procedure..$^{98}$

These computations were carried out with the Gaussian 09 suite of programs. ${ }^{99}$ DFT geometry optimization and interaction energies were also evaluated at the BLYP-D3/Def2TZVPP ${ }^{100-102}$ level of theory using the Gaussian 09 package. This DFT functional was recommended by Hobza et al. for complexes stabilized by noncovalent interactions of the sort being considered here. ${ }^{103}$ Energy decomposition analysis (EDA) was performed at the BLYP-D3/ZORA/TZ2P level using the ADF program. ${ }^{104-106}$

The molecular electrostatic potentials (MEPs) of the isolated monomers were calculated on the electron density isosurface of 0.001 a.u. at the MP2/cc-pVTZ level, and the extrema were extracted using the WFA-SAS program. ${ }^{107}$ MP2 electron densities were analyzed via AIM in order to characterize the individual intermolecular interactions. ${ }^{108}$ The noncovalent interaction index (NCI) was calculated at the MP2/cc-pVTZ level by means of the MultiWFN program. ${ }^{109-110}$

\section{Results}

\subsection{Electrostatic potentials of monomers}

As a first step toward forming each of the complexes, the molecular electrostatic potential (MEP) surrounding each molecule ought to attract its partner at long range via a Coulombic interaction. The positive region of the Lewis acid is characterized by the maximum of the MEP on a surface surrounding it that encompasses all points with a common electron density, which is typically take to be 0.001 au. These quantities, denoted $\mathrm{V}_{\mathrm{s}, \max }$, are reported in Table 1 and obey several trends. 
Table 1. Molecular electrostatic potentials extrema $\left(\mathrm{V}_{\mathrm{s}, \max }\right.$ and $\mathrm{V}_{\mathrm{s}, \min }$ in $\left.\mathrm{kcal} / \mathrm{mol}\right)$ on the 0.001 au isodensity contour of isolated monomers calculated at the MP2/cc-pvtz level of theory.

\begin{tabular}{|c|c|c|c|c|c|}
\hline $\mathrm{TF}_{4}$ & $\mathrm{~V}_{\mathrm{S}, \max }$ & $\mathrm{ZF}_{5}$ & $\mathrm{~V}_{\mathrm{S}, \text { max }}$ & base & $\mathrm{V}_{\text {S,min }}$ \\
\hline $\mathrm{SiF}_{4}$ & +41.3 & $\mathrm{PF}_{5}$ & +31.0 & $\mathrm{NCH}$ & -32.2 \\
\hline $\mathrm{GeF}_{4}$ & +50.9 & $\mathrm{AsF}_{5}$ & +39.1 & $\mathrm{NH}_{3}$ & -39.5 \\
\hline $\mathrm{SnF}_{4}$ & +70.1 & $\mathrm{SbF}_{5}$ & +54.1 & pyrazine & -29.8 \\
\hline
\end{tabular}

In the first place, the tetrel molecules $\mathrm{TF}_{4}$ have a considerably larger value of $\mathrm{V}_{\mathrm{s} \text {,max }}$ than do their pnicogen counterparts, for those atoms in the same row of the periodic table. For example, this quantity for $\mathrm{SiF}_{4}$ exceeds that of $\mathrm{PF}_{5}$ by some $10 \mathrm{kcal} / \mathrm{mol}$, and this margin grows as one proceeds down Table 1 toward larger atoms. As a second issue, $\mathrm{V}_{\mathrm{s} \text {, max }}$ grows larger for heavier atoms, e.g. $\mathrm{Si}<\mathrm{Ge}<\mathrm{Sn}$. Both of these trends are consistent with the idea that atoms of lesser electronegativity ought to be associated with larger $\mathrm{V}_{\mathrm{s} \text {,max }}$. With regard to the position of these points of maximal MEP, they are located directly opposite a particular T-F or Z-F covalent bond. $\mathrm{TF}_{4}$ is tetrehedral, so $\mathrm{V}_{\mathrm{s}, \max }$ occupies each of the four faces of this molecule. The $\mathrm{ZF}_{5}$ molecules are trigonal bipyramids, so their three maxima lie in the equatorial plane, directly between each pair of P-F bonds. The $\mathrm{V}_{\mathrm{s} \text {,min }}$ points of the three bases are all superimposed on the classical direction of the $\mathrm{N}$ lone pair. It is most negative for $\mathrm{NH}_{3}$, followed by $\mathrm{NCH}$ and then pyrazine.

\subsection{Equilibrium Geometries}

The structures of the complexes are illustrated in Fig. 1. As anticipated the $\mathrm{N}$ of each base approaches the $\mathrm{TF}_{4}$ molecule directly opposite a $\mathrm{T}-\mathrm{F}$ bond (designated $\mathrm{T}-\mathrm{F}_{1}$ ) aligned with $\mathrm{V}_{\mathrm{s} \text {,max. }}$. The situation is a bit more complicated for the $\mathrm{ZF}_{5}$ complexes, as the approach of the base causes the $\mathrm{ZF}_{5}$ molecule to rearrange from a strict trigonal bipyramid to a square pyramid shape, with the $\mathrm{N}$ lying opposite the apex $\mathrm{F}_{1}$ atom. Details of these geometries are displayed in Table 2. 

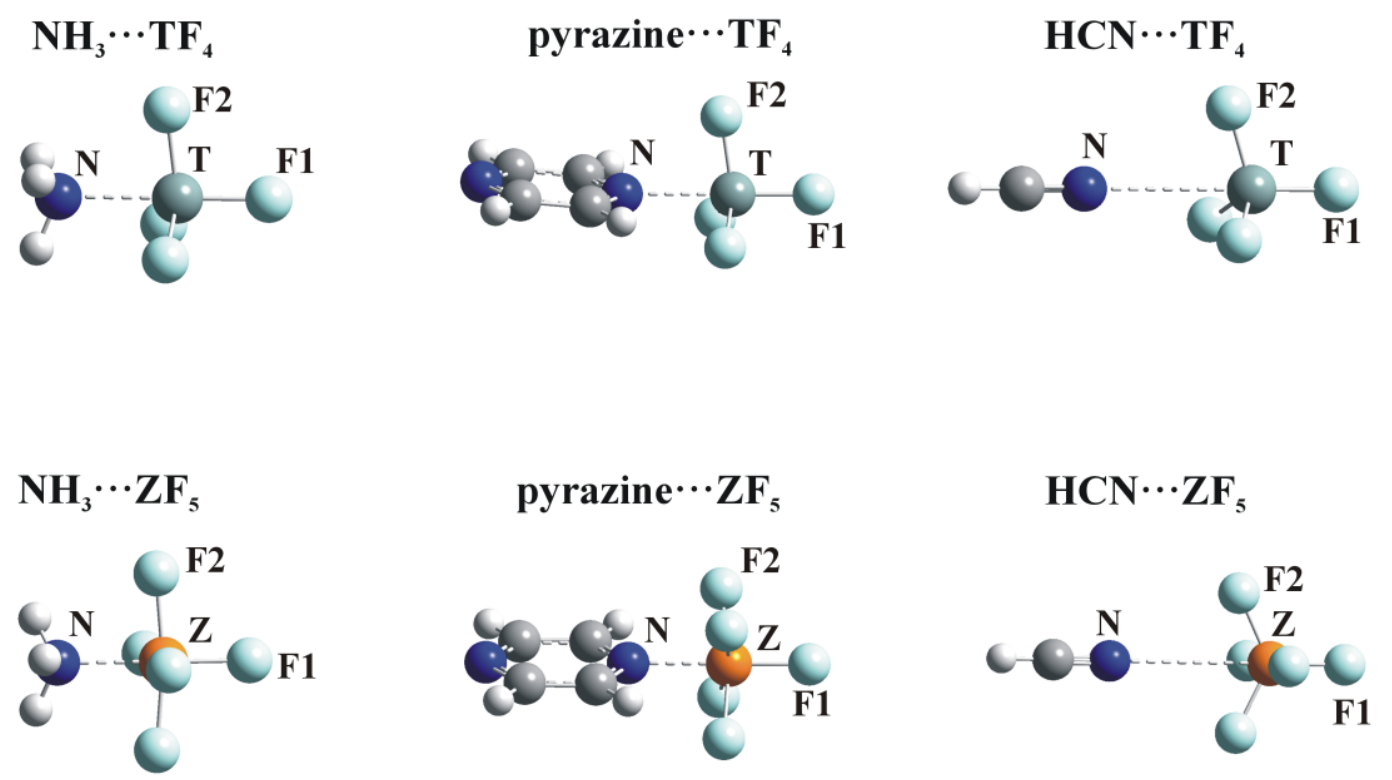

Fig. 1 Tetrel and pnicogen-bonded complexes, $\mathrm{T}=\mathrm{Si}, \mathrm{Ge}, \mathrm{Sn} ; \mathrm{Z}=\mathrm{P}, \mathrm{As}, \mathrm{Sb}$.

TABLE 2. Geometric parameters (distances in $\AA$, angles in degs) in complexes at the MP2/cc-pVTZ. $\mathrm{R}(\mathrm{N} \cdots \mathrm{T} / \mathrm{Z})$ distance also reported as percentage of the sum of the corresponding covalent radii $\left(\Sigma \mathrm{r}_{\mathrm{cov}}\right)$.

\begin{tabular}{|c|c|c|c|c|}
\hline Complex & $\mathrm{R}(\mathrm{N} \cdots \mathrm{T} / \mathrm{Z})$ & $\%$ of $\Sigma r_{\mathrm{cov}}$ & $\angle \mathrm{F}_{1}-\mathrm{T} / \mathrm{Z}-\mathrm{F}_{2}{ }^{\mathrm{a}}$ & $\Delta\left(\angle \mathrm{F}_{1}-\mathrm{T} / \mathrm{Z}-\mathrm{F}_{2}\right)^{\mathrm{b}}$ \\
\hline $\mathrm{NH}_{3} \cdots \mathrm{SiF}_{4}$ & 2.096 & 115 & 97.6 & -11.9 \\
\hline $\mathrm{NH}_{3} \cdots \mathrm{GeF}_{4}$ & 2.107 & 110 & 97.2 & -12.3 \\
\hline $\mathrm{NH}_{3} \cdots \mathrm{SnF}_{4}$ & 2.253 & 107 & 98.2 & -11.3 \\
\hline $\mathrm{NH}_{3} \cdots \mathrm{PF}_{5}$ & 1.933 & 109 & 94.4 & -25.6 \\
\hline $\mathrm{NH}_{3} \cdots \mathrm{AsF}_{5}$ & 2.017 & 106 & 94.8 & -25.2 \\
\hline $\mathrm{NH}_{3} \cdots \mathrm{SbF}_{5}$ & 2.179 & 104 & 95.9 & -24.1 \\
\hline pyrazine $\cdots \mathrm{SiF}_{4}$ & 2.198 & 121 & 99.0 & -10.5 \\
\hline pyrazine ${ }^{\cdots} \mathrm{GeF}_{4}$ & 2.149 & 113 & 97.5 & -12.0 \\
\hline pyrazine ${ }^{\cdots} \mathrm{SnF}_{4}$ & 2.265 & 108 & 99.1 & -10.4 \\
\hline pyrazine $\cdots \mathrm{PF}_{5}$ & 1.967 & 111 & 94.4 & -25.6 \\
\hline pyrazine $\cdots \mathrm{AsF}_{5}$ & 2.035 & 107 & 94.4 & -25.6 \\
\hline pyrazine ${ }^{\cdots} \mathrm{SbF}_{5}$ & 2.184 & 104 & 95.4 & -24.6 \\
\hline
\end{tabular}




\begin{tabular}{|c|c|c|c|c|}
\hline $\mathrm{HCN}^{\cdots} \mathrm{SiF}_{4}$ & 3.115 & 171 & 107.7 & -1.8 \\
\hline $\mathrm{HCN}^{\prime} \cdots \mathrm{GeF}_{4}$ & 2.604 & 136 & 103.8 & -5.7 \\
\hline $\mathrm{HCN}^{2} \cdots \mathrm{SnF}_{4}$ & 2.366 & 113 & 100.3 & -9.2 \\
\hline $\mathrm{HCN} \cdots \mathrm{PF}_{5}$ & 3.304 & 186 & 115.6 & -4.4 \\
\hline $\mathrm{HCN} \cdots \mathrm{AsF}_{5}$ & 2.179 & 115 & 97.0 & -23.0 \\
\hline $\mathrm{HCN}^{\cdots} \cdots \mathrm{SbF}_{5}$ & 2.263 & 108 & 97.1 & -22.9 \\
\hline
\end{tabular}

${ }^{\mathrm{a}} \angle \mathrm{F}_{1}-\mathrm{X}-\mathrm{F}_{2}$ in isolated $\mathrm{TF}_{4}$ and $\mathrm{ZF}_{5}$ are 109.5 and $120.0^{\circ}$, respectively

${ }^{\mathrm{b}}$ difference between complex and isolated molecule

There are a number of patterns which warrant elaboration. The intermolecular distances are shortest for $\mathrm{NH}_{3}$, with pyrazine only slightly longer; those involving $\mathrm{HCN}$ are considerably longer. For the two former bases, moving down a column of the periodic table elongates the intermolecular distance, e.g. $\mathrm{Si}<\mathrm{Ge}<\mathrm{Sn}$, but only slightly. The tetrel bonds are shorter than the pnicogen bonds for these same two bases, e.g. $\mathrm{R}\left(\mathrm{NH}_{3} \cdots \mathrm{SbF}_{5}\right)<\mathrm{R}\left(\mathrm{NH}_{3} \cdots \mathrm{SnF}_{4}\right)$. It is interesting that these trends reverse for complexes involving HCN. The second column of Table 2 focuses on the lengths of these bonds as a percentage of the sum of the covalent radii of the two atoms involved. For example, $\mathrm{R}\left(\mathrm{NH}_{3} \cdot \mathrm{SiF}_{5}\right)$ of $2.096 \AA$ is larger $(115 \%)$ than the covalent radii sum of $\mathrm{N}+\mathrm{Si}$.

It was noted above that the formation of the pnicogen bond forces the $\mathrm{ZF}_{5}$ molecule to distort from trigonal bipyramid to square pyramid. There is a like trend for the $\mathrm{TF}_{4}$ molecule to deform from strictly tetrahedral to a shape approaching a trigonal pyramid, with the central tetrel atom located nearly in its base. One measure of this distortion is the angle between the $F_{1}$ atom opposite the base, and any of the other $F$ atoms within the molecule (designated $\mathrm{F}_{2}$ ). These angles are displayed in the penultimate column of Table 2. Their deviation from their value in the uncomplexed monomer $\left(109.5^{\circ}\right.$ for $\mathrm{TF}_{4}$ and $120^{\circ}$ for $\left.\mathrm{ZF}_{5}\right)$ is tabulated in the last column. The incoming base forces apart the three $\mathrm{F}$ atoms of the $\mathrm{TF}_{4}$ face to which it will attach itself, pushing them closer to the opposite $\mathrm{F}_{1}$ atom, as is illustrated in Fig. S1 for a pair of select dimers. The relevant angle diminishes by some $10-12^{\circ}$, less for the HCN base. Note that this angular deformation is not very dependent on the identity of the $\mathrm{T}$ atom, again with the exception of $\mathrm{HCN}$. The $\mathrm{ZF}_{5}$ molecule undergoes a more fundamental geometry change, going from trigonal bipyramid in the monomer, to a square pyramid (see Fig. S1). The base approaches opposite one of the three equatorial $\mathrm{F}$ atoms, which is labeled $\mathrm{F}_{1}$. This atom was originally disposed some $120^{\circ}$ from the two other equatorial $\mathrm{F}$ atoms in the monomer. The latter two atoms are pushed away from the approaching base, and up toward $F_{1}$ in the complex, diminishing the $F_{1}-Z-F_{2}$ angle down below $100^{\circ}$ in most 
cases. The deformation in this angle is thus on the order of $25^{\circ}$, with a single exception of $\mathrm{HCN}^{\cdots} \mathrm{PF}_{5} \mathrm{with}^{\mathrm{a}}$ much smaller distortion.

\subsection{Energetic Consequences of Monomer Deformations}

The energetics of the binding are contained in Table 3 which lists the interaction energy of the pre-deformed monomers. That is, $\mathrm{E}_{\mathrm{int}}$ refers to the difference in energy between the complex and the sum of the monomers when in the geometries they will ultimately adopt within the complex. In all cases, NCH forms a much weaker complex than either $\mathrm{NH}_{3}$ or pyrazine which are comparable to one another. The pnicogen bonds are considerably stronger than the tetrel bonds, with the former approaching $50 \mathrm{kcal} / \mathrm{mol}$ in some cases. Whether tetrel or pnicogen, the bonds grow stronger for heavier atoms, i.e. $\mathrm{P}<\mathrm{As}<\mathrm{Sb}$. The DFT data are fairly similar to MP2, and reproduce all of the same trends. (The sole exception is the interaction of $\mathrm{SiF}_{4}$ with pyrazine which DFT predicts to be much weaker than does MP2.) To insure quantitative accuracy, CCSD(T) calculations were performed with the triple- $\zeta$ cc-pVTZ basis set. The interaction energies listed in the last column of Table 3 are all within $1 \mathrm{kcal} / \mathrm{mol}$ of the MP2 data, confirming the accuracy of the latter. This agreement applies as well to the $\mathrm{SiF}_{4}$ /pyrazine complex for which DFT provides an outlier data point.

Table 3. Interaction energy ( $\mathrm{E}_{\mathrm{int}}$, in $\left.\mathrm{kcal} / \mathrm{mol}\right)$ corrected for BSSE,calculated at the MP2/ cc-pVTZ (I), BLYP-D3/Def2TZVPP (II), and CCSD(T)/cc-pVTZ (III) levels of theory. ${ }^{\text {a }}$

\begin{tabular}{|l|c|c|c|}
\hline Complex & (I) & (II) & (III) \\
\hline $\mathrm{NH}_{3} \cdots \mathrm{SiF}_{4}$ & -26.38 & -22.48 & -26.73 \\
\hline $\mathrm{NH}_{3} \cdots \mathrm{GeF}_{4}$ & -31.23 & -29.66 & -31.34 \\
\hline $\mathrm{NH}_{3} \cdots \mathrm{SnF}_{4}$ & -35.29 & -32.87 & -35.32 \\
\hline $\mathrm{NH}_{3} \cdots \mathrm{PF}_{5}$ & -42.80 & -37.06 & -42.58 \\
\hline $\mathrm{NH}_{3} \cdots \mathrm{AsF}_{5}$ & -45.28 & -40.25 & -45.04 \\
\hline $\mathrm{NH}_{3} \cdots \mathrm{SbF}_{5}$ & -46.77 & -41.26 & -46.72 \\
\hline & & & \\
\hline pyrazine $\cdots \mathrm{SiF}_{4}$ & -20.80 & -8.44 & -20.62 \\
\hline pyrazine $\cdots \mathrm{GeF}_{4}$ & -29.33 & -28.27 & -28.98 \\
\hline pyrazine $\cdots \mathrm{SnF}_{4}$ & -34.50 & -32.03 & -34.09 \\
\hline pyrazine $\cdots \mathrm{PF}_{5}$ & -40.99 & -35.80 & -40.07 \\
\hline pyrazine $\cdots \mathrm{AsF}_{5}$ & -45.17 & -40.83 & -44.29 \\
\hline pyrazine $\cdots \mathrm{SbF}_{5}$ & -47.30 & -41.86 & -46.70 \\
\hline & & & \\
\hline HCN $\cdots \mathrm{SiF}_{4}$ & -2.63 & -2.57 & -2.55 \\
\hline
\end{tabular}




\begin{tabular}{|c|c|c|c|}
\hline $\mathrm{HCN}^{\cdots} \mathrm{GeF}_{4}$ & -6.76 & -4.98 & -6.52 \\
\hline $\mathrm{HCN}^{\cdots} \mathrm{SnF}_{4}$ & 16.99 & -13.92 & -16.53 \\
\hline $\mathrm{HCN} \cdots \mathrm{PF}_{5}$ & -2.35 & -2.23 & -2.23 \\
\hline $\mathrm{HCN}^{\cdots} \mathrm{AsF}_{5}$ & -17.77 & -13.73 & -16.88 \\
\hline $\mathrm{HCN}^{\cdots} \mathrm{SbF}_{5}$ & -24.56 & -19.51 & -23.90 \\
\hline
\end{tabular}

${ }^{a} \mathrm{MP} 2$ and DFT interaction energies computed using respective optimized geometries; CCSD(T) use MP2 geometries.

The interaction energies have certain consistencies with the MEP data in Table 1. For example, both show a pattern of enhancement with heavier atoms. On the other hand, there are major inconsistencies as well. For example, $\mathrm{V}_{\mathrm{s}, \max }$ is larger for tetrel than for pnicogen atoms, in contrast to the opposite pattern for $\Delta \mathrm{E}_{\text {int. }}$ While $\mathrm{V}_{\mathrm{s} \text {,min }}$ is more negative for $\mathrm{NCH}$ than for pyrazine, it is the latter that engages in the stronger bonds. Clearly then, mere consideration of extrema on the MEP diagram is not sufficient to predict energetics.

There are a number of ways to characterize this type of interaction. A decomposition of the total interaction energy into its various components is reported in Table S1. This data indicates that the electrostatic component is fairly large, representing somewhat more than $50 \%$ of the total attractive force. This contribution is greater than $60 \%$ for the tetrel bonds, and between 50 and $60 \%$ for the pnicogen bonds. Orbital interactions represent a smaller component, between 32 and 43\%. The trend is the opposite of that for electrostatics, as the orbital interactions contribute a higher percentage for the pnicogen than for the tetrel bonds. Dispersion is quite small, generally $5 \%$ or less. The pattern is a bit different for $\mathrm{NCH}$ complexes, where the electrostatic and orbital interaction energies are very small for the complexes with $\mathrm{SiF}_{4}$ and $\mathrm{PF}_{5}$.

AIM provides indications of the locations of intermolecular bonds via analysis of the electron density topology. Graphs of the bond paths are illustrated in Fig. S2 for some representative systems. There is a small green sphere along the line connecting $\mathrm{N}$ to the Ge or As atoms in Fig. S2. Other indications of these bonds appear in the NCI diagrams in Fig. S3. On a more quantitative level, the electron densities at each T/Z $\cdot \mathrm{N}$ bond critical point are reported in Table 4. Many of the trends conform to the energetics in Table 3.

Table 4. Electron density at T/Z•NN AIM bond critical point (au), computed at the MP2/cc-pVTZ level of theory.

\begin{tabular}{|c|c|c|c|}
\hline & $\mathrm{NH}_{3}$ & pyrazine & $\mathrm{NCH}$ \\
\hline $\mathrm{SiF}_{4}$ & 0.059 & 0.048 & $0.024^{\mathrm{a}}$ \\
\hline $\mathrm{GeF}_{4}$ & 0.078 & $0.072(0.014)^{\mathrm{b}}$ & 0.022 \\
\hline
\end{tabular}




\begin{tabular}{|c|c|c|c|}
\hline $\mathrm{SnF}_{4}$ & 0.071 & $0.070(0.013)^{\mathrm{b}}$ & 0.048 \\
\hline $\mathrm{PF}_{5}$ & 0.110 & 0.103 & 0.008 \\
\hline $\mathrm{AsF}_{5}$ & 0.107 & 0.104 & 0.064 \\
\hline $\mathrm{SbF}_{5}{ }^{\mathrm{a}}$ & $0.13^{\mathrm{a}}$ & $0.136^{\mathrm{a}}$ & $0.12^{\mathrm{a}}$ \\
\hline
\end{tabular}

${ }^{a}$ no $\mathrm{T} / \mathrm{Z} \cdot \mathrm{N}$ BCP. Values shown indicate sum of FN BCPs.

${ }^{b}$ Value in parentheses refer to each secondary intermolecular $\mathrm{H} \cdot \mathrm{F}$ BCPs

For example, $\rho_{\mathrm{BCP}}$ is larger for the pnicogen than for the tetrel bonds, and $\mathrm{NH}_{3}$ is involved in the strongest bonds, and $\mathrm{NCH}$ the weakest. On the other hand, AIM incorrectly suggests that Ge engages in stronger tetrel bonds than does Sn, and fails to differentiate between P and As. AIM moreover suggests that there are $\mathrm{CH} \cdot \cdot \mathrm{F}$ $\mathrm{HBs}$, albeit weak ones, involving pyridine's $\mathrm{H}$ atoms, when combined with $\mathrm{SiF}_{4}$ and $\mathrm{GeF}_{4}$. Notably, there is no bond path between $\mathrm{Si}$ and $\mathrm{NCH}$, nor between $\mathrm{Sb}$ and any of the bases. It would appear then that while AIM and MEP data provide some useful information, their ability to fully and completely analyze and predict energetics is limited, especially when monomers are deformed during the complexation process.

Since there is very substantial geometric deformation occurring in these complexes, it is important to interrogate its energetic consequence. The deformation energies imposed on the monomers in order to form the optimized complex are displayed in the first three columns of Table 5.

Table 5. Deformation energies ( $E_{\text {def }}$ ) of monomers within complexes and binding energy $E_{b}$, computed at the MP2/cc-pVTZ level of theory. All values are in $\mathrm{kcal} / \mathrm{mol}$.

\begin{tabular}{|c|c|c|c|c|c|c|}
\hline & \multicolumn{3}{|c|}{$\mathrm{E}_{\text {def }}$} & \multicolumn{3}{c|}{$\mathrm{E}_{\mathrm{b}}$} \\
\hline & $\mathrm{NH}_{3}$ & pyrazine & $\mathrm{NCH}$ & $\mathrm{NH}_{3}$ & pyrazine & $\mathrm{NCH}$ \\
\hline $\mathrm{SiF}_{4}$ & 20.29 & 16.79 & 0.44 & -6.09 & -4.01 & -2.19 \\
\hline $\mathrm{GeF}_{4}$ & 16.90 & 17.45 & 3.41 & -14.33 & -11.88 & -3.35 \\
\hline $\mathrm{SnF}_{4}$ & 10.26 & 11.62 & 6.22 & -25.03 & -22.88 & -10.77 \\
\hline $\mathrm{PF}_{5}$ & 23.26 & 23.43 & 0.65 & -19.54 & -17.56 & -1.70 \\
\hline $\mathrm{AsF}_{5}$ & 16.53 & 18.18 & 9.22 & -28.75 & -26.99 & -8.55 \\
\hline $\mathrm{SbF}_{5}$ & 9.41 & 11.34 & 6.54 & -37.36 & -35.96 & -18.02 \\
\hline
\end{tabular}


These quantities are quite large, exceeding $20 \mathrm{kcal} / \mathrm{mol}$ in some cases. As in the case of the interaction energies, the $\mathrm{NH}_{3}$ and pyrazine complexes are associated with the largest strain energies, much more than $\mathrm{NCH}$. With the exception of the latter base, there is a clear tendency of lowering strain energy for larger T/Z atoms. For example, the deformation energy of $\mathrm{SiF}_{4} \cdots \mathrm{NH}_{3}$ is cut in half for $\mathrm{SnF}_{4} \cdots \mathrm{NH}_{3}$. Although the largest distortion energies arise with $\mathrm{PF}_{5}$, there is little distinction between tetrel and pnicogen bonds in this regard.

The binding energy of a complex consists of the energy of the full reaction going from a pair of isolated monomers to the complex. This quantity $\mathrm{E}_{\mathrm{b}}$ thus differs from the interaction energy by the strain that must be imposed on the two monomers.

After correcting $\mathrm{E}_{\text {int }}$ by the deformation energies, one arrives at the binding energies contained in the last three columns of Table 5 which are considerably less exothermic than are the interaction energies in Table 3. Unlike $E_{\text {int, }}$ the binding energies show a profound sensitivity to the nature of the $T / Z$ atom rising quickly for heavier atoms. For example, $\mathrm{E}_{b}$ rises by a factor of 4 on going from $\mathrm{SiF}_{4} \cdots \mathrm{NH}_{3}$ to $\mathrm{SnF}_{4} \cdots \mathrm{NH}_{3}$. Pnicogen bonds are considerably stronger than their tetrel analogues, as for example a threefold enhancement from $\mathrm{SiF}_{4} \cdots \mathrm{NH}_{3}$ to $\mathrm{PF}_{5} \cdots \mathrm{NH}_{3}$.

\subsection{Implications of Monomer Deformations}

As described above, the monomer deformations are quite significant for most of these complexes. One might wonder what would happen if the two monomers were allowed to interact with one another, but without the freedom to modify their internal geometries. For example, if the three $\mathrm{F}$ atoms of $\mathrm{TF}_{4}$ were not permitted to peel back toward the fourth $\mathrm{F}$ as the base approached. Or likewise if the $\mathrm{ZF}_{5}$ molecules retained their trigonal bipyramid shape. In fact, all of these complexes would form anyway but with greatly reduced interaction energies. As shown by the first three columns of Table 6, the interaction energies between the frozen monomers are quite small, generally less than $6 \mathrm{kcal} / \mathrm{mol}$.

The largest such frozen interaction energies arise for $\mathrm{SnF}_{4}$, but still remains under $13 \mathrm{kcal} / \mathrm{mol}$. The loss of this interaction energy as a result of this freezing is displayed in the last three columns of Table 6 and reaches up to over $40 \mathrm{kcal} / \mathrm{mol}$. It might be concluded that the geometry changes are very important but not completely necessary for these tetrel and pnicogen bonds to form. It is interesting to note finally that both $\mathrm{E}_{\text {int }}$ in Table 3 and $E_{b}$ in Table 5 were larger in magnitude for pnicogen than for tetrel bonds. But the frozen interaction energies in Table 6 paint a different picture of stronger tetrel bonds. As was done above for interaction energies in fully optimized complexes, these same quantities using frozen geometries were also checked for accuracy via $\operatorname{CCSD}(\mathrm{T})$ calculations. As may be seen by the quantities in parentheses in Table 6, the MP2 values are again quite accurate. 
Table 6. Interaction energies (kcal/mol) computed at the MP2/cc-pVTZ level of theory with the Lewis acid frozen in its geometry within the optimized dimer. $\operatorname{CCSD}(\mathrm{T}) / \mathrm{cc}-\mathrm{pVTZ}$ results are in parentheses.

\begin{tabular}{|l|l|l|l|l|l|l|}
\hline & \multicolumn{5}{|l|}{$\mathrm{E}_{\text {int }}($ froz $)$} & \multicolumn{2}{l|}{$\mathrm{E}_{\text {int }}(\mathrm{froz})-\mathrm{E}_{\text {int }}$} \\
\hline & $\mathrm{NH}_{3}$ & pyrazine & $\mathrm{NCH}$ & $\mathrm{NH}_{3}$ & pyrazine & $\mathrm{NCH}$ \\
\hline $\mathrm{SiF}_{4}$ & $-2.98(-3.12)$ & $-3.25(-3.24)$ & $-1.89(-1.82)$ & $23.40(23.61)$ & $17.55(17.38)$ & $0.74(0.73)$ \\
\hline $\mathrm{GeF}_{4}$ & $-4.68(-4.88)$ & $-4.93(-4.89)$ & $-2.64(-2.55)$ & $26.55(26.46)$ & $24.40(24.09)$ & $4.12(3.97)$ \\
\hline $\mathrm{SnF}_{4}$ & $-12.26(-12.46)$ & $-11.17(-10.95)$ & $-5.44(-5.18)$ & $23.03(22.86)$ & $23.33(23.14)$ & $11.55(11.35)$ \\
\hline & & & & & & \\
\hline $\mathrm{PF}_{5}$ & $-1.96(-2.02)$ & $-2.27(-2.22)$ & $-1.84(-1.74)$ & $40.84(40.56)$ & $38.72(37.85)$ & $0.51(0.49)$ \\
\hline $\mathrm{AsF}_{5}$ & $-2.70(-2.80)$ & $-2.94(-2.88)$ & $-1.89(-1.80)$ & $42.58(42.24)$ & $42.23(41.41)$ & $15.88(15.08)$ \\
\hline $\mathrm{SbF}_{5}$ & $-5.84(-5.98)$ & $-6.19(-6.11)$ & $-3.13(-2.99)$ & $40.93(40.74)$ & $41.11(40.59)$ & $21.43(20.91)$ \\
\hline
\end{tabular}

It is the latter pattern that conforms to expectations derived from the values of $\mathrm{V}_{\mathrm{s}, \max }$ in Table 1. The latter observation brings up an important point. The geometry changes occurring within the $\mathrm{TF}_{4}$ and $\mathrm{ZF}_{5}$ molecules as they form complexes with the bases have other implications as well. For example, the values of $\mathrm{V}_{\mathrm{s}, \max }$ in Table 1 refer to the unperturbed fully tetrahedral structure of $\mathrm{TF}_{4}$. But as the three $\mathrm{F}$ atoms of this molecule bend back away from the approaching base, one might anticipate an associated change in its MEP. The alteration in the trigonal pyramid geometry of $\mathrm{ZF}_{5}$ to square planar ought to likewise produce significant MEP perturbations. In fact, there are rather large increases found in the value of $\mathrm{V}_{\mathrm{s}, \max }$ that lies in the direction of the approaching base when the Lewis acid adopts its geometry within each complex. This increase can be more than a factor of 2 as is clear from the data in Table 7, and is rather large even for the weaker complexes formed by $\mathrm{NCH}$.

Table 7. Magnitude of $\mathrm{V}_{\mathrm{s}, \max }(\mathrm{kcal} / \mathrm{mol})$ on $\mathrm{T} / \mathrm{Z}$ atom of isolated $\mathrm{TF}_{4} / \mathrm{ZF}_{5}$ molecule and its value when the molecule is distorted to that within the complex. Calculations performed at the MP2/cc-pVTZ level.

\begin{tabular}{|c|c|c|c|c|c|c|c|}
\hline & $\begin{array}{c}\text { optimized } \\
\text { monomer }\end{array}$ & \multicolumn{3}{c|}{ in complex geometry } & \multicolumn{3}{c|}{ change } \\
\hline & & $\mathrm{NH}_{3}$ & pyrazine & $\mathrm{NCH}$ & $\mathrm{NH}_{3}$ & pyrazine & NCH \\
\hline $\mathrm{SiF}_{4}$ & 41.3 & 92.3 & 88.3 & 48.2 & +51.0 & +47.0 & +6.9 \\
\hline $\mathrm{GeF}_{4}$ & 50.9 & 97.2 & 98.0 & 73.1 & +46.3 & +47.1 & +22.2 \\
\hline $\mathrm{SnF}_{4}$ & 70.1 & 108.0 & 109.7 & 102.4 & +37.9 & +39.6 & +32.3 \\
\hline & 31.0 & & & & & & +5 \\
\hline $\mathrm{PF}_{5}$ & 39.1 & 89.8 & 89.7 & 42.0 & +58.8 & +58.7 & +11.0 \\
\hline $\mathrm{AsF}_{5}$ & 54.1 & 98.6 & 99.4 & 92.8 & +59.5 & +60.3 & +53.7 \\
\hline $\mathrm{SbF}_{5}$ & & 113.3 & 114.4 & 110.8 & +59.2 & +60.3 & +56.7 \\
\hline
\end{tabular}


Given the large changes in $\mathrm{V}_{\mathrm{s} \text {,max }}$ as the Lewis acid deforms so as to best accommodate the approaching acid, it would be interesting to see whether these changes occur smoothly or in a more sudden manner. In other words, does a trigonal pyramidal molecule like $\mathrm{AsF}_{5}$ retain its shape until the base is very close, or does it reshape smoothly and gradually? As a second point, does $\mathrm{V}_{\mathrm{s}, \max }$ increase monotonically and gradually during this rearrangement. One can see how the MEP changes as the base approaches in Fig. 2.

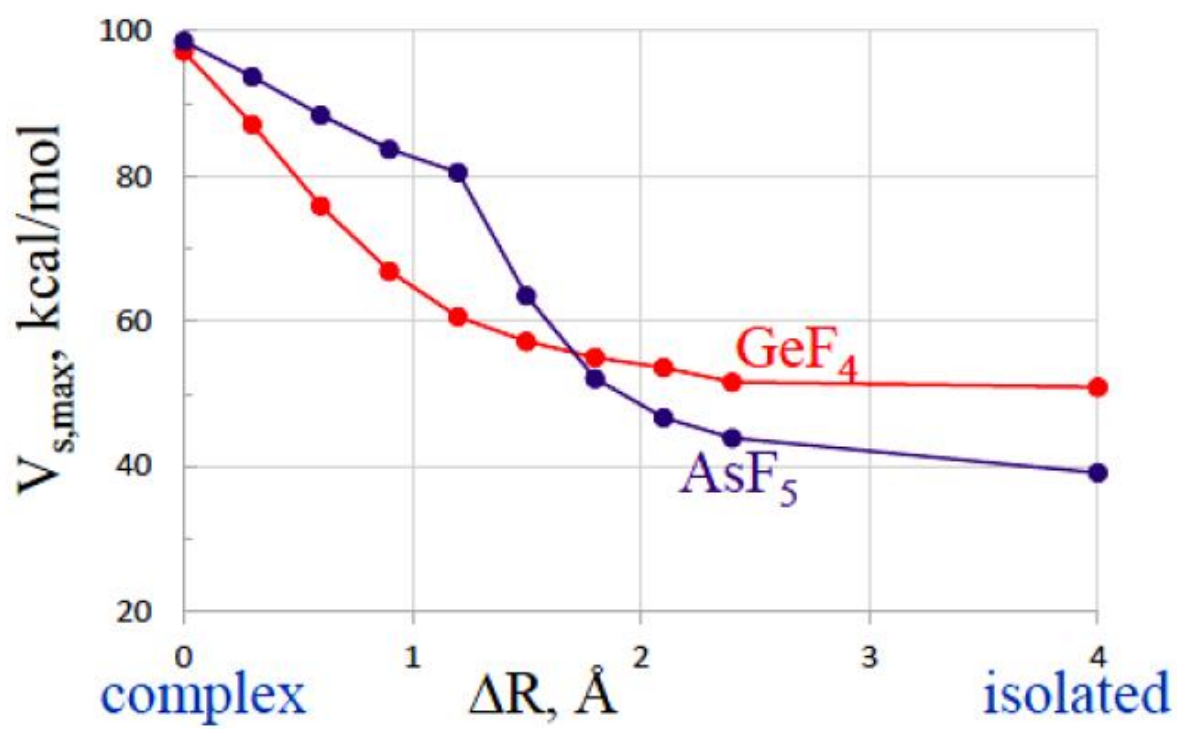

Fig. 2. Behavior of $\mathrm{V}_{\mathrm{s}, \max }$ as the indicated Lewis acid distorts as $\mathrm{NH}_{3}$ approaches, with $\Delta \mathrm{R}$ equal to the stretch from the equilibrium geometry of the dimer.

$\mathrm{GeF}_{4}$ was taken as the sample tetrel bonding acid and $\mathrm{AsF}_{5}$ as the pnicogen unit, in both cases with $\mathrm{NH}_{3}$ as the approaching base. $\Delta \mathrm{R}$ is defined as the stretch of the $\mathrm{Ge} / \mathrm{As} \cdot{ }^{*} \mathrm{~N}$ intermolecular distance from its equilibrium value in the fully optimized dimer. As one moves leftward from the far right, symbolizing the fully isolated $\mathrm{GeF}_{4}$ Lewis acid, there is a fairly gradual, but steady increase in $\mathrm{V}_{\mathrm{s}, \max }$ until the $\mathrm{NH}_{3}$ is within about $2 \AA$ of its equilibrium separation, at which point the increase picks up a bit, again rising steadily. The increase is a bit more precipitous for $\mathrm{AsF}_{5}$ in the $1 \AA<\Delta \mathrm{R}<2 \AA$ region, but again is a monotonic rise as the acid deforms. Another view of this increase is presented in Fig. S4 where one may easily see the increasingly red, i.e. positive, nature of the $\sigma$-hole as the base approaches.

It is further intriguing to observe how the gradual staged approach of the base affects the various components of the interaction energy. Of course, all components diminish as the two subunits are pulled away 
from one another, as can be seen by the data in Tables S2 and S3. This drop in each attractive component is illustrated in Fig. 3 for the same two sample tetrel and pnicogen-bonded systems.

a)

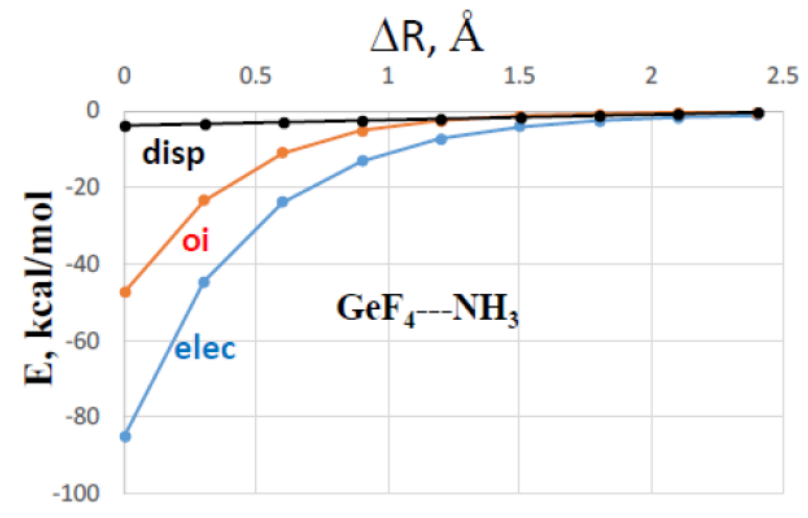

b)

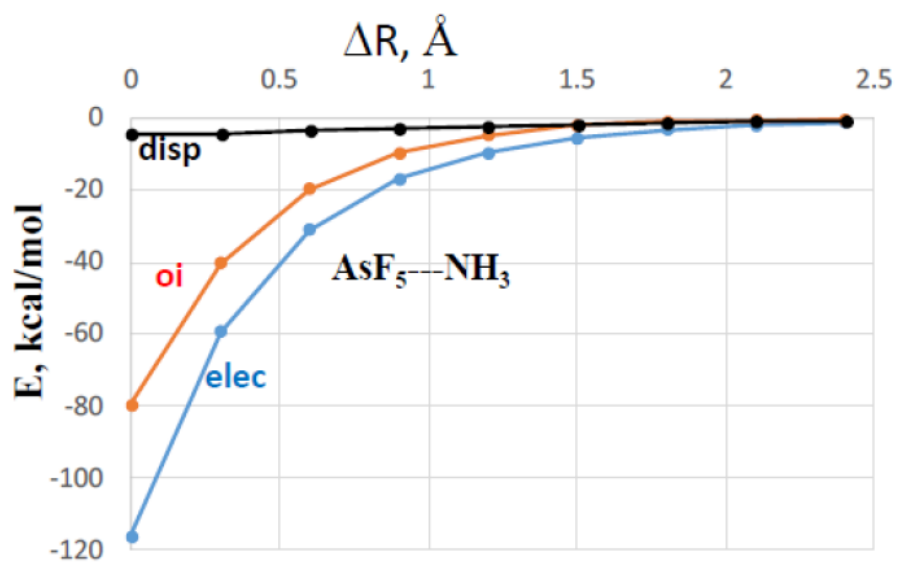

Fig. 3. Attractive contributions to total interaction energy in a) $\mathrm{GeF}_{4} \cdots \mathrm{NH}_{3}$ and b) $\mathrm{AsF}_{5} \cdots \mathrm{NH}_{3}$ as the intermolecular distance $\mathrm{R}$ is stretched.

One would ordinarily expect to see the electrostatic term decrease less quickly with distance than the other two components, given the longer-range nature of Coulombic forces. But the blue elec curve in Fig. 3 seems to drop surprisingly quickly. Perhaps a better view of this behavior can be gleaned from Fig. 4 which presents the three terms on a percentage basis.

a)

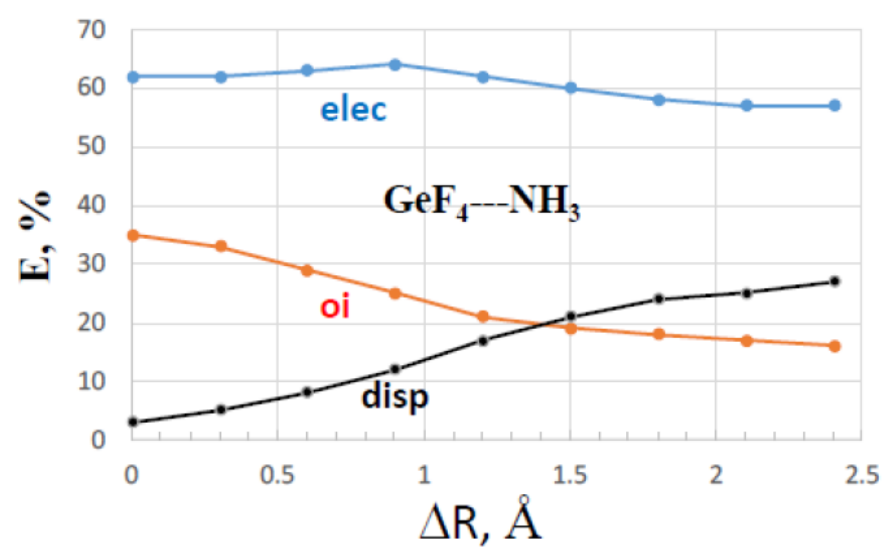

b)

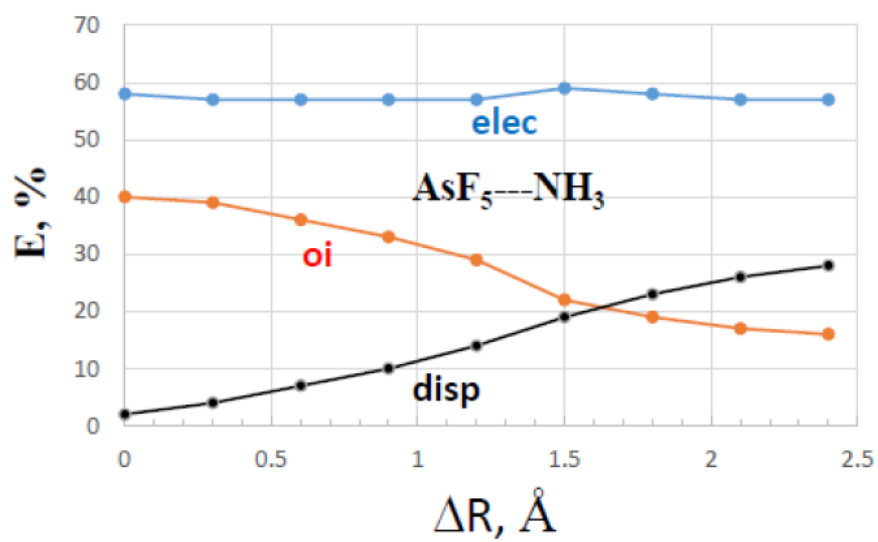

Fig. 4. Percentage contributions to total interaction energy of each component in a) $\mathrm{GeF}_{4} \cdots \mathrm{NH}_{3}$ and b) $\mathrm{AsF}_{5} \cdots \mathrm{NH}_{3}$ as the intermolecular distance $\mathrm{R}$ is stretched. 
As a short-range interaction, the orbital interaction term ought to diminish at longer separation, and the red curves in Fig. 4 do just that, dropping from about $40 \%$ to $15 \%$ as $\mathrm{R}$ is stretched by $2.5 \AA$ A. Again, due to its long-range character, the electronic contribution is anticipated to increase its fractional contribution at longer intermolecular separations. But the blue curve in Fig. 4 remains steady at roughly 60\%, and even shows a slight drop in the case of the tetrel bond. Even though dispersion is a fairly small component, never exceeding 5 $\mathrm{kcal} / \mathrm{mol}$, its fractional contribution rises as the orbital interaction terms drops more quickly. As a result the oi and disp curves cross one another at a stretch of roughly $1.5 \AA$. To what can one attribute the surprisingly rapid drop-off of the electrostatic term? The behavior of $\mathrm{V}_{\mathrm{s}, \max }$ in Fig. 2 offers an insight into the matter. As the two molecules move apart, the Lewis acid rearranges its shape, and as it does so the positive MEP represented by the $\sigma$-hole is reduced in magnitude which in turn accelerates the drop in the electrostatic attractive energy.

The forgoing presents the idea that the monomer deformation helps to augment the electrostatic attractive force between the two monomers. But one might expect that there are steric effects at play as well, due to the crowded nature of the substituents surrounding each Lewis acid. The Heitler-London interaction $\left(\Delta \mathrm{E}_{\mathrm{HL}}\right)$ represents the sum of electrostatic attraction and Pauli repulsion, i.e. without allowing any modification of orbitals, polarization, etc. As the two molecules approach one another, the long-range nature of Coulombic forces dominates and $\Delta \mathrm{E}_{\mathrm{HL}}$ is negative. However, as shown in Fig. S5, the magnitudes of these two terms reverse when the two molecules come to within about $0.5 \AA$ of their equilibrium separation, and the overall sum $\Delta \mathrm{E}_{\mathrm{HL}}$ rises very quickly as they continue their approach. This quantity is rather large within the equilibrium structure, about $25 \mathrm{kcal} / \mathrm{mol}$ for $\mathrm{GeF}_{4} \cdots \mathrm{NH}_{3}$ and twice that magnitude for $\mathrm{AsF}_{5} \cdots \mathrm{NH}_{3}$. One can conclude that steric repulsions represent a major factor that causes the deformation of the monomer geometry within each complex, supplementing the ability of the distortion to raise the electrostatic attraction. The magnitude of these repulsions is echoed by NCI diagrams of the equilibrium structures where they appear between the base and the pertinent $\mathrm{T} / \mathrm{Z}-\mathrm{F}$ bonding regions.

Because of its importance, it is interesting to consider the process of geometrical distortion in greater detail, particularly throughout the process when the complex is being formed from two separate monomers. As noted above, the $\mathrm{ZF}_{5}$ molecules are trigonal bipyramidal in shape, so thus have a pair of axial ligands, and three equatorial ligands, as displayed in Fig. 5. 

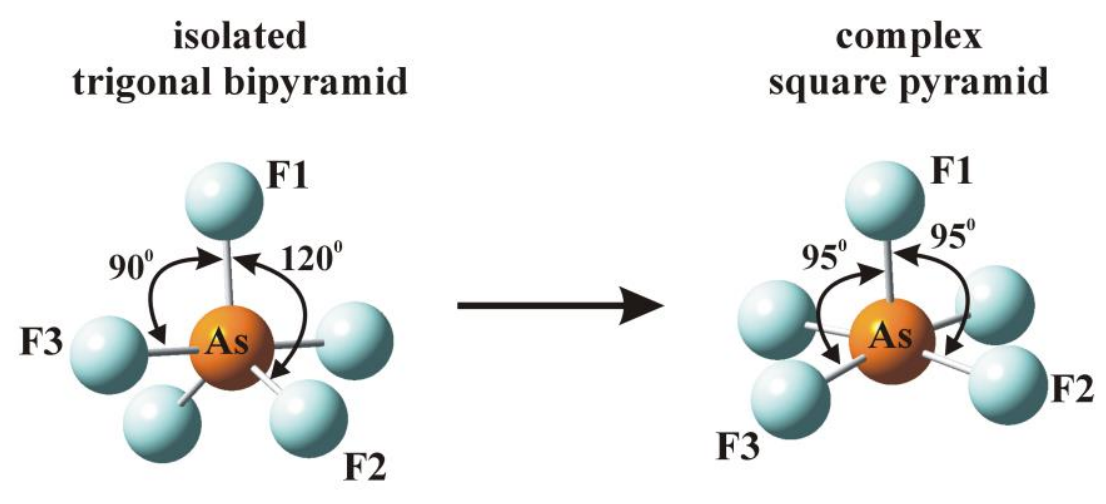

Fig. 5. Angles defined for $\mathrm{AsF}_{5}$ within monomer and complex.

A nucleophile will be drawn in toward the equatorial plane, opposite one of these ligands (denoted $\mathrm{F}_{1}$ ), as it is here where the $\sigma$-holes lie. The ensuing rearrangement will ultimately lead to a square pyramidal shape, with $\mathrm{F}_{1}$ at the apex. All four of the $\theta\left(F_{1} Z F\right)$ angles will thus adopt the same value in this final pyramid, e.g. $95^{\circ}$ in the case of $\mathrm{AsF}_{5}{ }^{*} \mathrm{NH}_{3}$. But there are two types of angles that are changing along the way. The angle between equatorial $\mathrm{F}_{1}$ and each of its equatorial neighbors $\left(\mathrm{F}_{2}\right)$ begins at $120^{\circ}$ and then diminishes to $95^{\circ}$, a drop of $25^{\circ}$. On the other hand, the $\theta\left(\mathrm{F}_{1} \mathrm{ZF}_{3}\right)$ angle between $\mathrm{F}_{1}$ and either of its axial neighbors $\mathrm{F}_{3}$ begins at $90^{\circ}$ in the original trigonal bipyramid, and then experiences a rise to $95^{\circ}$.

Fig. 6 shows that the latter of the two angles changes monotonically and fairly smoothly as the $\mathrm{NH}_{3}$ approaches $\mathrm{AsF}_{5}$, but with a fairly sharp drop when the $\mathrm{R}(\mathrm{As} \cdot \cdot \mathrm{N})$ distance diminishes from 1.5 to $1.2 \AA$. The behavior of the $\theta\left(\mathrm{F}_{1} \mathrm{ZF}_{3}\right)$ angle is rather different.

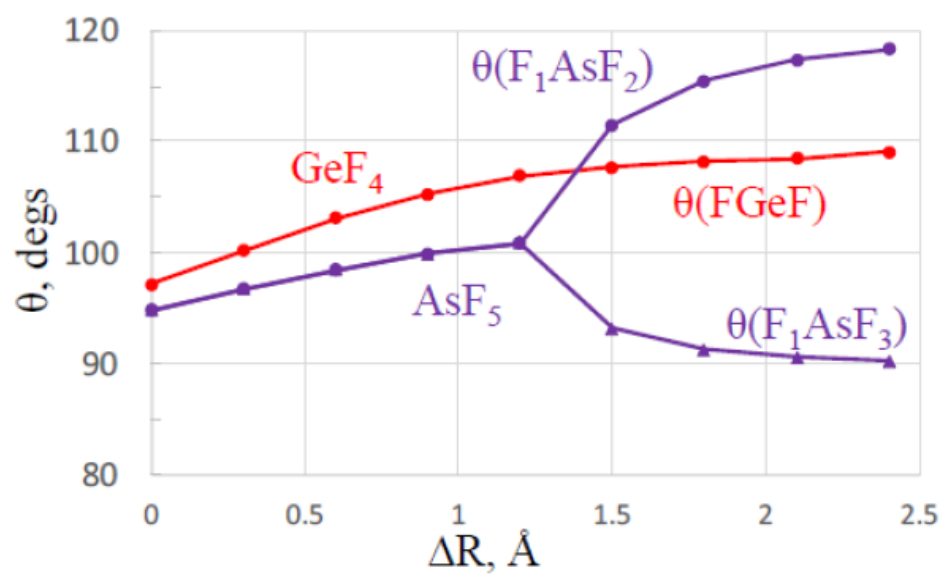

Fig. 6. Internal angles within $\mathrm{AsF}_{5}$ and $\mathrm{GeF}_{4}$ as the $\mathrm{NH}_{3}$ molecule is pulled away from the equilibrium geometry. 
Starting from its monomer value of $90^{\circ}$, it rises at first, especially for $\Delta \mathrm{R}$ between 1.5 and $1.2 \AA$. At the latter point, the monomer adopts its ultimate square pyramid shape, and the two angles become equivalent. They both then diminish smoothly toward the equilibrium structure at $\Delta \mathrm{R}=0$. The symmetry of the $\mathrm{TF}_{4}$ molecules is such that all three of the $\theta\left(\mathrm{F}_{1} \mathrm{TF}\right)$ angles are equivalent as the base approaches (where $\mathrm{F}_{1}$ again designates the atom opposite the base). The behavior of this angle is also depicted in Fig. 6 where it displays a fairly steady decline from right to left as the approaching base pushes the $\mathrm{F}$ atoms closer together.

\section{Discussion and Conclusions}

One can seek verification for some of the geometrical ideas via a search of the Cambridge Structural Database (CSD). ${ }^{111}$ Fig. S6a and S6b display the geometries of systems wherein $\mathrm{GeCl}_{4}$ and $\mathrm{SnCl}_{4}$ ) respectively engage in a tetrel bond with a $\mathrm{N}$-base. It is immediately clear that the $\mathrm{GeCl}_{4}$ molecule, whether paired with $\mathrm{NMe}_{3}$ or quinuclidine, has adopted a trigonal pyramid shape, just as the various $\mathrm{TF}_{4}$ molecules discussed above. The $\mathrm{R}(\mathrm{Ge} \cdot \mathrm{N})$ distance in $\mathrm{GeCl}_{4} \cdots \mathrm{NMe}_{3}$ is $2.195 \AA$, rather close to the intermolecular distance of $2.107 \AA$ in Table 2, despite the different substituents on both the Ge and $\mathrm{N}$ atoms. The $\mathrm{Sn} \cdot \mathrm{N}$ distance in the $\mathrm{SnCl}_{4} \cdot$.quinuclidine complex is only slightly longer at $2.282 \AA$. With respect to $\mathrm{ZF}_{5}$ pnicogen-bonded complexes, geometries observed in crystals adhere to the square pyramidal shapes illustrated in Fig. 1 for pentavalent $\mathrm{PF}_{5},{ }^{77-80} \mathrm{AsF}_{5},{ }^{81-90}$ and $\mathrm{SbF}_{5}{ }^{91-93}$ adducts with miscellaneous $\mathrm{N}$-donors including heteroaromatics, azoles, pyridine derivatives and linear aliphatic molecules.

Further confirmation of the ideas described here comes also from prior calculations. The ability of monomer deformations to strongly affect the value of $\mathrm{V}_{\mathrm{s}, \mathrm{max}}$, by as much as a factor of 4 , was observed ${ }^{63}$ for the pyrazine $\cdots \mathrm{ZX}_{5}(\mathrm{Z}=\mathrm{P}, \mathrm{As}, \mathrm{Sb}$ and $\mathrm{X}=\mathrm{F}, \mathrm{Cl}, \mathrm{Br})$ set of complexes, as the $\mathrm{ZX}_{5}$ molecule altered its geometry from trigonal bipyramid to square pyramid. For these systems too, the leading contributor to the binding was the electrostatic component. Other workers have also found ${ }^{64}$ large enhancements in $\mathrm{V}_{\mathrm{s}, \max }$ as a result of a similar rearrangement in $\mathrm{AsF}_{5}$ and $\mathrm{SbF}_{5}$ at the M06-2X/6-311G(d) level of theory. Similar geometric rearrangements as those observed here were also noted ${ }^{53}$ in tetrel-bonded complexes involving $\mathrm{TF}_{4}$ and $\mathrm{NH}_{3}$, along with similar intermolecular distances, and binding energies that were slightly larger, but which nevertheless followed the same pattern. $\mathrm{NH}_{3} \cdots \mathrm{SiF}_{4}$ and $\mathrm{HCN}^{\cdots} \mathrm{SiF}_{4}$ were also examined ${ }^{112}$ by Marín-Luna et al . whose computed data are in good coincidence with our own, and the same can be said for the M06-2X/6$311 \mathrm{G}(\mathrm{d})$ binding energies of $\mathrm{HCN}^{\cdots} \mathrm{SiF}_{4}$ and $\mathrm{HCN}^{\cdots} \mathrm{GeF}_{4}$ reported ${ }^{24}$ by Grabowski, although the former was a bit inflated.

It should be understood that geometric distortions of the type and magnitude discussed here may not always be possible, for example within the confines of a macromolecular skeleton which restricts such rearrangements. The calculations suggest that tetrel and pnicogen bonds would be substantially weakened by such circumstances 
to only a small fraction of the bond energy that is experienced in the absence of such restraints. The amount of this weakening ought to be directly related to the degree of restraint placed upon the substituents which reduce their ability to adjust to the incoming base. These findings thus have important implications for understanding the role that such noncovalent bonds may play in molecular structure and function.

In conclusion, the formation of tetrel bonds involves a very substantial geometric distortion of the Lewis acid in order to accommodate the incoming base. Three of the substituents bend back away from the base, distorting its normally tetrahedral geometry into a trigonal pyramid shape. Similar issues arise for pnicogen bonds involving a pentavalent central atom where the Lewis acid deforms from a trigonal bipyramid into a square pyramid. The deformation energy of the acid molecule is a major player in the reaction/binding energy, which is much less exothermic than is the actual interaction energy between pre-deformed monomers. The effects of monomer distortion are inversely related to the size of the central atom, greatest for the smaller Si and $\mathrm{P}$ atoms. Given the importance of electrostatic attraction to these noncovalent bonds, it is worth stressing that the MEP adjusts itself to the changing shape of the Lewis acid. The $\sigma$-hole intensifies dramatically as the acid deforms so as to fit the base, and this in turn yields a very substantial boost to the Coulombic attractive energy.

\section{Conflicts of interest}

There are no conflicts to declare.

\section{Acknowledgements}

This work was financed in part by a statutory activity subsidy from the Polish Ministry of Science and Higher Education for the Faculty of Chemistry of Wroclaw University of Science and Technology. A generous computer time from the Wroclaw Supercomputer and Networking Center is acknowledged.

\section{References}

[1]G. Gilli and P. Gilli, The Nature of the Hydrogen Bond, Oxford University Press, Oxford, UK, 2009. [2]G. R. Desiraju and T. Steiner, The Weak Hydrogen Bond in Structural Chemistry and Biology, Oxford University Press, New York, 1999.

[3]S. Scheiner, Hydrogen Bonding. A Theoretical Perspective, Oxford University Press, New York, 1997. [4]T. Clark, M. Hennemann, J.S. Murray and P. Politzer, J. Mol. Model., 2007, 13, 291.

[5]J. S. Murray, P. Lane and P. Politzer, J. Mol. Model., 2009, 15, 723.

[6]J. S. Murray, P. Lane and P. Politzer, Int. J. Quantum Chem., 2007, 107, 2286.

[7]P. Politzer, P. Lane, M. Concha, Y. Ma and J. S. Murray, J. Mol. Model., 2007, 13, 305.

[8]P. Politzer, J. S. Murray and M. C. Concha, J. Mol. Model., 2008, 14, 659.

[9]J. S. Murray, P. Lane, T. Clark, K. E. Riley and P. Politzer, J. Mol. Model., 2012, 18, 541.

[10]J. S. Murray, M. C. Concha, P. Lane, P. Hobza and P. Politzer, J. Mol. Model., 2008, 14, 699.

[11]P. Politzer, and J. S. Murray, Crystals, 2017, 7, 212. 
[12]G. R. Desiraju, P.S. Ho, L. Kloo, A.C. Legon, R. Marquardt, P. Metrangolo, P. Politzer, G. Resnati and K. Rissanen, Pure Appl. Chem., 2013, 85, 1711.

[13]G. Terraneo and G. Resnati, Cryst. Growth Des., 2017, 17, 1439.

[14]G. Cavallo, P. Metrangolo, R. Milani, T. Pilati, A. Priimagi, G. Resnati and G. Terraneo, Chem. Rev., 2016, 116, 2478.

[15]K.E. Riley, C. L. Ford, and K. Demouchet, Chem. Phys. Lett., 2015, 621, 165.

[16]S. K. Nayak, V. Kumar, J. S. Murray, P. Politzer, G. Terraneo, T. Pilati,

P. Metrangolo and G. Resnati, CrystEngComm 2017, 19, 4855.

[17] V. d. P. N. Nziko and S. Scheiner, J. Phys. Chem. A, 2015, 119, 5889.

[18] M. D. Esrafili and F. Mohammadian-Sabet, Int. J. Quantum Chem., 2016, 116, 529.

[19] L. M. Azofra, I. Alkorta and S. Scheiner, J. Phys.Chem. A, 2015, 119, 535.

[20]A. Bauza, T. J. Mooibroek and A. Frontera, ChemPhysChem, 2016, 17, 1608.

[21]G. Sanchez-Sanz, C. Trujillo, I. Alkorta and J. Elguero, Phys. Chem. Chem. Phys., 2016, 18, 9148.

[22]F. Liu, L. Du, J. Gao, L. Wang, B. Song and C. Liu, J. Comput. Chem.,2015, 36, 441.

[23]J. Joy, A. Jose and E. D. Jemmis, J. Comput. Chem., 2016, 37, 270.

[24]S. Grabowski, Phys. Chem. Chem. Phys., 2014, 16, 1824.

[25] D. Mani and E. Arunan, J. Phys. Chem. A, 2014, 118, 10081.

[26] M. Marín-Luna, I. Alkorta and J. Elguero, J. Phys. Chem. A, 2016, 120, 648.

[27] Q. Tang and Q. Li, Comput. Theor. Chem., 2014, 1050, 51.

[28] K. E. Riley and P. Hobza, J. Chem. Theory Comput., 2008, 4, 232.

[29] S. Tsuzuki and N. Sato, J. Phys. Chem. A, 2013, 117, 6849.

[30] J. Rezac and A. De la Lande, Phys. Chem. Chem. Phys., 2017, 19, 791.

[31]A. Bauza and A. Frontera, Angew. Chem. Int. Ed., 2015, 54, 7340.

[32]A. Bauza and A. Frontera, ChemPhysChem, 2015, 16, 3625 .

[33]A. Bauza and A. Frontera, Phys.Chem.Chem.Phys., 2015, 17, 24748.

[34]S. Scheiner, Acc. Chem. Res., 2012, 46, 280.

[35]J. E. Del Bene, I. Alkorta, G. Sánchez-Sanz and J. Elguero, J. Phys. Chem. A, 2011, 115,13724.

[36]M. D. Esrafili, F. Mohammadian-Sabet and M. Solimannejad, J. Mol. Graph. Model. 2015, 57, 99.

[37]C. Liu, Y. Zeng, X. Li, L. Meng and X. Zhang, J. Mol. Model., 2015, 21, 143.

[38]R. Shukla and D. Chopra, Phys. Chem. Chem. Phys., 2016, 18, 13820.

[39]M. Esrafili, F. Mohammadian-Sabet and E. Vessally Mol. Phys., 2016, 114, 2115.

[40]I. Alkorta and J. Elguero, J. Phys. Chem. A, 2013, 117, 4981.

[41]J. E. Del Bene, I. Alkorta and J. Elguero, J. Phys. Chem. A, 2013, 117,11592.

[42]J. E. Del Bene, I. Alkorta and J. Elguero, J. Phys. Chem. A, 2014, 118, 3386.

[43]J. E. Del Bene, I. Alkorta and J. Elguero, J. Phys. Chem. A, 2014, 118, 2360.

[44]X. L. An, R. Li, Q. Z. Li, X. F. Liu, W. Z. Li and J. B. Cheng, J. Mol. Model., 2012, 18, 4325.

[45]S. Scheiner, J. Phys. Chem. A, 2011, 115, 11202.

[46]M. D. Esrafili, M. Vakili and M. Solimannejad, Chem. Phys. Lett., 2014, 609, 37.

[47]M. D Esrafili, P. Fatehi and M. Solimannejad, Comput. Theor. Chem., 2014, 1034,1.

[48]H. Y. Zhuo, Q. Z. Li, W. Z. Li and J. B. Cheng, New. J. Chem., 2015, 39, 2067.

[49]A. Bauzá and A. Frontera, Crystals, 2016, 6, 26.

[50]M. D. Esrafili and F.Mohammadian-Sabet, Mol. Phys., 2016, 114, 1528. 
[51]M.Liu, Q. Li and S. Scheiner, Phys. Chem. Chem. Phys., 2017, 19, 5550.

[52]M. Liu, Q. Li, W. Li and J. Cheng, J. Mol. Graphics Model., 2016, 65, 35.

[53]S. Scheiner, J. Phys. Chem. A 2017, 121, 5561.

[54] V. d. P. N. Nziko and S. Scheiner, Phys. Chem. Chem. Phys., 2016, 18, 3581.

[55]K.T. Mahmudov, M.N. Kopylovich, M.F.C. Guedes da Silva and A.J.L. Pombeiro, Coord. Chem. Rev., 2017, 345, 54-72.

[56]L. Guan and Y. Mo, J. Phys. Chem. A, 2014, 118, 8911.

[57]S. Zahn, R. Frank, E. Hey-Hawkins and B. Kirchner, Chem. Eur. J. 2011, 17, 6034.

[58]E. Abroushan, A. Zabaradsti, S. Farhadi and A. Abodolmaleki, Struct. Chem. 2017, $28,1843$.

[59]A. Bauzá, R. Ramis and A. Frontera, Comput. Theor. Chem., 2014, 1038, 67.

[60]S. Scheiner, J. Phys. Chem. A, 2017, 121, 3606.

[61]M. Liu, Q. Li, J. Cheng, W. Li and H.-B Li, J. Chem. Phys. 2016, 145, 224310.

[62]S. Scheiner, Chem. Eur. J., 2016, 22, 18850.

[63] J. Fanfrlík, W. Zierkiewicz, P. Švec, J. Rezac, M. Michalczyk, Z. Ruzickova, A. Ruzicka, D. Michalska and P. Hobza, J. Mol. Model., 2017, 23, 128.

[64]P. Scilabra, G. Terraneo and G. Resnati, J. Fluorine Chem., 2017, 203, 62.

[65]A.J. Edwards, J. Chem. Soc. A, 1970, 2751.

[66] J.F. Sawyer and R.J. Gillespie, Progr. Inorg. Chem., 1986, 34, 65.

[67] S.L. Benjamin, J. Burt, W. Levason, G. Reid and M. Webster, J. Fluorine Chem., 2012, 135, 108.

[68]M. Bourgault, R. Fourcade, B. Ducourant and G. Mascherpa, Rev. Chim. Miner., 1979, 16, 151.

[69]M.S. Fonari, Y.A. Simonov, V.C. Kravtsov, J. Lipkowski, G. Bocelli, E.V. Ganin and V.O. Gelmboldt, J Chem. Cryst., 1999, 29, 1245.

[70] M.S. Fonari, E.V. Ganin, V.O. Gelmboldt, J. Lipkowski, S.A. Kotlyar and G.L. Kamalov, Acta Crystallogr. Sect. E: Struct., 2006, 62, m1021.

[71] P. Farina, W. Levason and G. Reid, Polyhedron, 2013, 55, 102.

[72] B. Alic, A. Stefancic and G. Tavcar, J. Chem. Soc. Dalton Trans., 2017, 46, 2246.

[73] G. Bombieri, G. Bruno, F. Nicolo, G. Alonzo and N. Bertazzi, J. Chem. Soc. Dalton

Trans., 1987, 10, 2451.

[74] P.L. Davidovich, V.V. Tkachev and L.O. Atovmyan, Koord. Khim., 1995, 21, 20.

[75] J.C. Dewan, A.J. Edwards, J.E. Guerchais and F. Petillon, J. Chem. Soc. Dalton Trans.

1975, 21, 2295.

[76] W. Levason, M.E. Light, S. Maheshwari, G. Reid and W.J. Zhang, J. Chem. Soc. Dalton

Trans. 2011, 40, 5291.

[77] T. Chong, N. Wanli, C. Qiao, S. Guofeng and M.V.Borzov, Izv.Akad.Nauk

SSSR,Ser.Khim.(Russ.)(Russ.Chem.Bull.), 2014, 2668.

[78] R.E. Dunmur, H. Thonnessen, C. Muller, M. Farkens, A. Fischer, P.G. Jones and R. Schmutzler, Chem.Ber., 1993, 126, 2653.

[79] W.S. Sheldrick, J. Chem. Soc. Dalton Trans., 1974, 1402.

[80] E. Lork, P.G. Watson and R. Mews, Chem.Commun., 1995, 1717.

[81] T.S. Cameron, A. Decken, M. Fang, S. Parsons, J. Passmore and D.J. Wood, Chem.Commun., $1999,1801$.

[82] H.W. Roesky, J. Sundermeyer, J. Schimkowiak, T. Gries, M. Noltemeyer and G.M. Sheldrick, Z.

Naturforsch. B: Chem. Sci., 1986, 41, 162. 
[83] A. Apblett, T. Chivers and J.F. Richardson, Can. J. Chem., 1986, 64, 849.

[84] S.-J. Chen, U. Behrens, F. Olbrich and R. Mews, Z. Anorg. Allg. Chem. 1993, 619, 1725.

[85] I.C. Tornieporth-Oetting, T.M. Klapötke, U. Behrens and P.S. White, J. Chem. Soc.

Dalton Trans., 1992, 2055.

[86] M. Schroter, E. Lork and R. Mews, Z. Anorg. Allg. Chem., 2005, 631, 1609.

[87] S. Bellard, A.V. Rivera and G.M. Sheldrick, Acta Crystallogr. Sect. B: Struct. Crystallogr. Cryst. Chem., 1978, 34, 1034.

[88] C.Knapp, E.Lork, R.Maggiulli, P.G.Watson, R.Mews, T.Borrmann, W.-D.Stohrer and U.Behrens, Z.Anorg.Allg.Chem., 2004, 630, 1235.

[89] R. Minkwitz, M. Koch, J. Nowicki and H. Borrmann, Z. Anorg. Allg. Chem., 1990, 590, 93.

[90] R.J. Gillespie, J.P. Kent and J.F. Sawyer, Acta Crystallogr.,Sect.B.Struct.Crystallogr.Cryst.Chem., 1980, 36, 655 .

[91] I.H.T. Sham, B.O. Patrick, B.von Ahsen, S.von Ahsen, H. Willner, R.C. Thompson and F. Aubke, Solid State Sciences, 2002, 4, 1457.

[92] I.C. Tornieporth-Oetting, T.M. Klapotke, T.S. Cameron, J. Valkonen, P. Rademacher and K. Kowski, J.Chem.Soc.,Dalton Trans., 1992, 537.

[93]Y. Nakajima, T. Tsuchimoto, Y.-H. Chang, K. Takeuchi and F. Ozawa, Dalton Trans., 2016, 45, 2079.

[94] C. Møller and M. S. Plesset, Phys. Rev., 1934, 46, 618.

[95] T. H. Dunning Jr., J. Chem. Phys., 1989, 90, 1007.

[96] D. Feller, J. Comp. Chem., 1996, 17, 1571.

[97] K.L. Schuchardt, B.T Didier. T. Elsethagen, L. Sun, V. Gurumoorthi, J. Chase, J. Li, and T.L Windus, J. Chem. Inf. Model., 2007, 47, 1045.

[98] S. F. Boys and F. Bernardi, Mol Phys., 1970, 19, 553.

[99] M. J. Frisch, G. W. Trucks, H. B. Schlegel, G. E. Scuseria, M. A. Robb, J. R. Cheeseman, G. Scalmani, V.

Barone, B. Mennucci, G. A. Petersson, H. Nakatsuji, M. Caricato, X. Li, H. P. Hratchian, A. F. Izmaylov, J.

Bloino, G. Zheng, J. L. Sonnenberg, M. Hada, M. Ehara, K. Toyota, R. Fukuda, J. Hasegawa, M. Ishida, T.

Nakajima, Y. Honda, O. Kitao, H. Nakai, T. Vreven, J. A. Montgomery Jr., J. E. Peralta, F. Ogliaro, M.

Bearpark, J. J. Heyd, E. Brothers, K. N. Kudin, V. N. Staroverov, R. Kobayashi, J. Normand, K. Raghavachari, A. Rendell, J. C. Burant, S. S. Iyengar, J. Tomasi, M. Cossi, N. Rega, J. M. Millam, M. Klene, J. E. Knox, J. B. Cross, V. Bakken, C. Adamo, J. Jaramillo, R. Gomperts, R. E. Stratmann, O. Yazyev, A. J. Austin, R. Cammi, C. Pomelli, J. W. Ochterski, R. L. Martin, K. Morokuma, V. G. Zakrzewski, G. A. Voth, P. Salvador, J. J. Dannenberg, S. Dapprich, A. D. Daniels, O. Farkas, J. B. Foresman, J.V. Ortiz, J. Cioslowski and D.J. Fox, Gaussian 09, Gaussian, Inc., Wallingford CT, 2009

[100] S. Grimme , J. Antony, S. Ehrlich and H. Krieg, J. Chem. Phys., 2010, 132, 154104.

[101] F. Weigend and R. Ahlrichs, Phys. Chem. Chem. Phys., 2005, 7, 3297-3305.

[102] F. Weigend, Phys. Chem. Chem. Phys., 2006, 8, 1057-1065.

[103] R. Sedlak, T. Janowski, M. Pitonak, J. Rezac, P. Pulay, P. Hobza J. Chem. Theory Comput., 2013, 9, 3364.

[104]G. te Velde, F. M. Bickelhaupt, E. J. Baerends, C. Fonseca Guerra, S. J. A. van Gisbergen, J. G. Snijders and T. Ziegler, J. Comput. Chem., 2001, 22, 931.

[105]C. Fonseca Guerra, J. G. Snijders, G. te Velde and E. J. Baerends, Theor. Chem. Acc., 1998, 99, 391.

[106]ADF2014, SCM, Theoretical Chemistry, Vrije Universiteit, Amsterdam, The Netherlands, http://www.scm.com. 
[107]F. Bulat, A. Toro-Labbe, T. Brinck, J.S. Murray and P. Politzer, J. Mol. Model., 2010, 161679.

[108]AIMAll (Version 14.11.23), Todd A. Keith, TK Gristmill Software, Overland Park KS, USA, 2014

(aim.tkgristmill.com)

[109]T. Lu and F. Chen, J. Comput. Chem., 2012, 33, 580.

[110]T. Lu and F. Chen, J. Mol. Graph. Model., 2012, 38, 314.

[111]The Cambridge Structural Database: C. R. Groom, I. J. Bruno, M. P. Lightfoot and S. C. Ward, Acta Cryst. 2016, B72, 171.

[112] M. Marín-Luna, I. Alkorta, and J. Elguero, Theor. Chem. Acc., 2017, 136, 41.

[113] M. S. Bilton and M. Webster, J. Chem. Soc., Dalton Trans., 1972, 722.

[114] W. A. Grigsby, T. S. Morien, C. L. Raston, B. W. Skelton and A. H. White, Australian Journal of

Chemistry, 2004, 57, 507. 